\title{
Microstructure and Mechanical Properties of TC18 Titanium Alloy
}

\author{
Sun Shuyu ${ }^{1}, \quad$ Lv Weijie ${ }^{2}$ \\ ${ }^{1}$ Taizhou University, Taizhou 318000, China; ${ }^{2}$ State Key Laboratory of Metal Matrix Composites, Shanghai Jiaotong University, Shanghai \\ 200240, China
}

\begin{abstract}
Ti}-5 \mathrm{Al}-5 \mathrm{Mo}-5 \mathrm{~V}-1 \mathrm{Fe}-1 \mathrm{Cr} \mathrm{Ti}$ alloy (TC18) was fabricated via a consumable vacuum arc-remelting furnace, and then subjected to thermo-mechanical processing and heat treatment. The microstructural characteristics and mechanical properties of the heat-treated alloy were investigated. Results show that primary $\alpha$ phase exhibits spherical, near equiaxed, plate- and rod-shaped morphologies after heat treatment. This is associated with boundary segregation of $\alpha$ grain. The alloy presents a good combination of strength and plasticity during tensile test. However, the value of $\sigma_{\mathrm{y}} / \sigma_{\mathrm{b}}$ of the alloy reaches 0.95 . It is suggested that the grain boundaries absorb dislocations during tensile test; therefore, the dislocation strengthening increases very slowly. This is the primary reason for the high value of $\sigma_{\mathrm{y}} / \sigma_{\mathrm{b}}$
\end{abstract}

Key words: TC18 Ti alloy; microstructure characteristics; mechanical properties; value of $\sigma_{\mathrm{y}} / \sigma_{\mathrm{b}}$

High-strength titanium alloys are widely used in aviation, aerospace and other economic sectors owing to their excellent combination of strength and toughness. The constant drive for higher specific properties has lead to continuous improvement of Ti alloy design ${ }^{[1-4]}$.

Ti-5Al-5Mo-5V-1Fe-1Cr (TC18) Ti alloy is one of important aviation material, which can be used as aeroplane parts and large force-bearing components. The mechanical properties of the alloy have been investigated in recent years ${ }^{[5-10]}$. However, little information is available to date on the value of $\sigma_{\mathrm{y}} / \sigma_{\mathrm{b}}$ (yield strength/ultimate strength) of the alloy during tensile test at room temperature. The aim of the present paper is to study the reasons why TC18 alloy possesses very high value of $\sigma_{\mathrm{y}} / \sigma_{\mathrm{b}}$ and what is the role of the load-bearing effect of $\alpha$ grain in TC18 Ti alloy microsturcture, so as to provide valuable technical information for further R\&D of TC18 Ti alloy.

\section{Experiment}

The raw materials were sponge $\mathrm{Ti}$ (grade I ) and other alloying elements including $\mathrm{Al}, \mathrm{Al}-\mathrm{Mo}, \mathrm{Al}-\mathrm{V}, \mathrm{Fe}$ and $\mathrm{Cr}$.
According to the stoichiometric composition of TC18 Ti alloy the above raw materials were blended together thoroughly and then compacted into pellets. The pellets were melted in a consumable vacuum at least twice to promote microstructure homogeneity.

The as-cast ingot was forged at $1150{ }^{\circ} \mathrm{C}$ and rolled at $840{ }^{\circ} \mathrm{C}$, and then is subjected to heat treatment. In order to control the overgrowth of grains and obtain good comprehensive mechanical properties, we employed triplex heat treatment procedures as follows: $830{ }^{\circ} \mathrm{C} / 1.5 \mathrm{~h}+$ furnace cooling, $750{ }^{\circ} \mathrm{C} / 1.5 \mathrm{~h}$ +air cooling, $600{ }^{\circ} \mathrm{C} / 4 \mathrm{~h}$ +air cooling.

The heat-treated rods were machined into the samples for tensile test at room temperature. Microstructure observations were conducted by optical microscope (OM) and scanning electron microscope (SEM) after the polishing and etching. Moreover, transmission electron microscope (TEM) was also used.

\section{Results and Discussion}

\subsection{Microstructure of the alloy}

Fig.1a shows the microstructure of the as-cast alloy. The $\alpha$

Received date: April 19, 2015

Foundation item: Research Program of Zhejiang Education Department (Y201533396)

Corresponding author: Sun Shuyu, Ph. D., Lecturer, School of Mechanical Engineering, Taizhou University, Taizhou 318000, P. R. China, Tel: 0086-576-88661930, E-mail: sun_shuyu@126.com

Copyright (C) 2016, Northwest Institute for Nonferrous Metal Research. Published by Elsevier BV. All rights reserved. 
grain shows needle-shaped morphology due to high contents of $\beta$ stabilizing elements. The microstructure of the alloy after thermo-mechanical processing is inhomogeneous (Fig.1b). Fig.1c shows the microstructure of the alloy undergoing the heat treatment. Since the segregation increases the anisotropy of the boundary migration of $\alpha$ grain, the primary $\alpha$ dispersing in $\beta$ phase shows spherical, near equiaxed, plate-shaped and rod-shaped morphologies. Fig.1d shows the characteristics of Widmannstatten structure. The high-stage temperature of the triplex heat treatment $\left(870{ }^{\circ} \mathrm{C}\right)$ is higher than the $\beta$ transus one $\left(865{ }^{\circ} \mathrm{C}\right)$. The boundary $\alpha$ decorating $\beta$ exerts Zener pinning force on the boundary migration of $\beta$ grain. The boundary $\alpha$ has a wide range of size distribution, which gives rise to a large Zener dragging force ${ }^{[11]}$. Moreover, the morphology diversity of the $\beta$ is also associated with grain boundary segregation.

Fig.2a shows TEM image of the alloy undergoing by heat treatment. The secondary $\alpha$ phase precipitates during aging. Fig. $2 \mathrm{~b}$ shows the secondary $\alpha$ with the annealing twins. The interfacial energy of the annealing twins is a stacking fault energy, which is significantly lower than that of LAGB (low angle grain boundaries) or HAGB (high angle grain boundaries). Since the precipitation temperature of the secondary $\alpha$ phase is relatively low, the secondary $\alpha$ is difficult to be spheroidized. Nevertheless, the lentoid shape of the secondary $\alpha$ is favorable for decreasing elastic strain energy caused by the difference of specific volume between $\alpha$ and $\beta$ phase. Fig.2c shows the dislocations in the primary $\alpha$. Dislocations may enter grain boundary of $\alpha$. Fig. $2 \mathrm{~d}$ shows the sub-grain of primary $\alpha$. When the high-stage temperature approaches to the $\beta$ transus temperature of the alloy, the defects such as sub-grain boundary and dislocations may form high diffusivity path. The segregation induces chemical potential gradient, which accelerates surface diffusion. $\beta$ stabilizing elements penetrate along the path into $\alpha$ which may lead to the division of $\alpha$ finally ${ }^{[12]}$.

\subsection{Mechanical properties of the alloy}

Table 1 is the mechamical properties of TC18 alloy.

Fig. 3 shows the features of dimple fracture. The equiaxed dimples distribute uniformly. The average size of the dimples is $4.3 \mu \mathrm{m}$. The tearing-mode cracks are observed. It is suggested that some dimples result from the fracture or interface debonding of secondary $\alpha$. The relatively large depths of the dimples indicate that the work-hardening parameter of the alloy is relatively low. Namely, the dislocation strengthening increases slowly during the process of the deformation. This is consistent with the result of the tensile test.

The dislocation strengthening is determined by the multiplication and pilling-up of dislocations. The slow increase in the stress indicates that the dislocation pilling-up increases slowly.

The segregation concentration of grain boundary increases under the effects of tensile stress ${ }^{[13]}$. The dislocations can enter grain boundaries under the effect of stress gradient, which can be also pinned by the segregated alloying elements in the grain boundaries. This will decrease the dislocation pilling-up in grains during tensile test significantly.

Table 1 Mechanical properties of TC18 alloy

\begin{tabular}{cccccc}
\hline$\sigma_{\mathrm{y}} / \mathrm{MPa}$ & $\sigma_{\mathrm{b}} / \mathrm{MPa}$ & $\varepsilon_{\mathrm{f}} / \mathrm{MPa}$ & $\varepsilon / \%$ & $\psi / \%$ & $\sigma_{\mathrm{y}} / \sigma_{\mathrm{b}}$ \\
\hline 1106 & 1160 & 15.1 & 13.5 & 19.7 & 0.95 \\
\hline
\end{tabular}

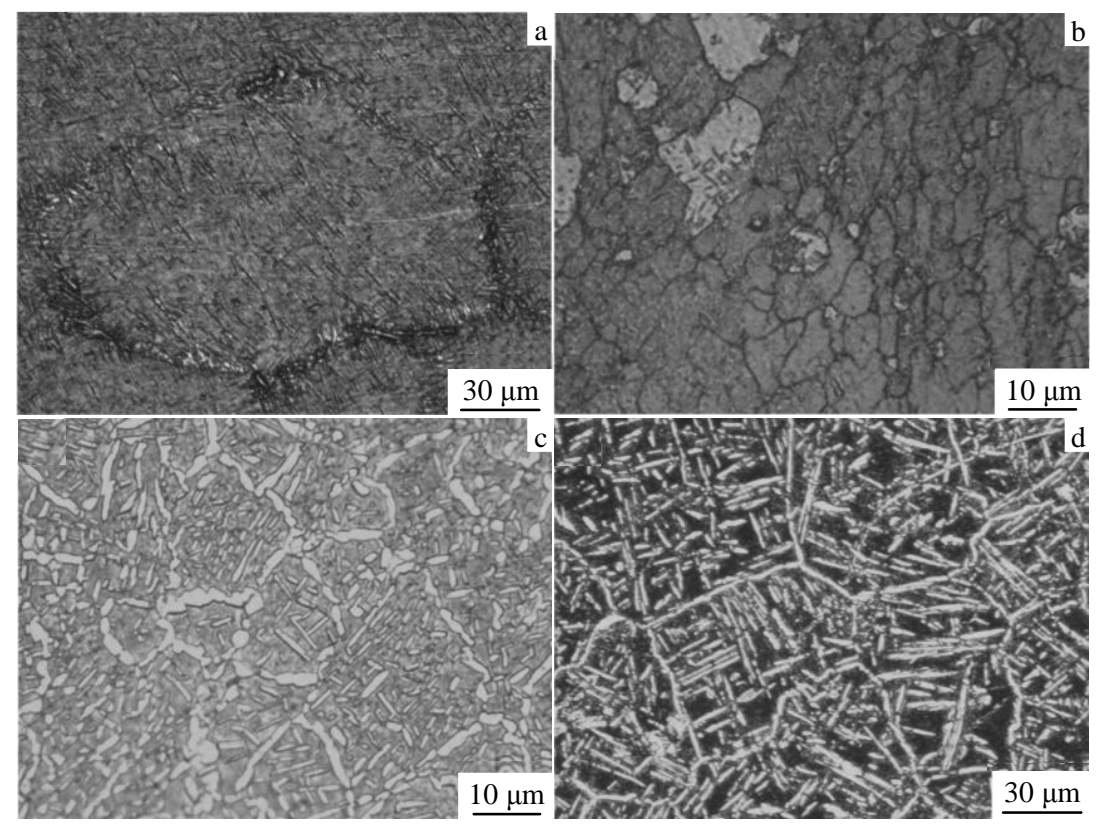

Fig.1 Optical micrographs of TC18 alloy: (a) the as-cast alloy; (b) the alloy after forging and rolling; (c) the alloy undergoing heat treatment; (d) Widmannstatten structure 

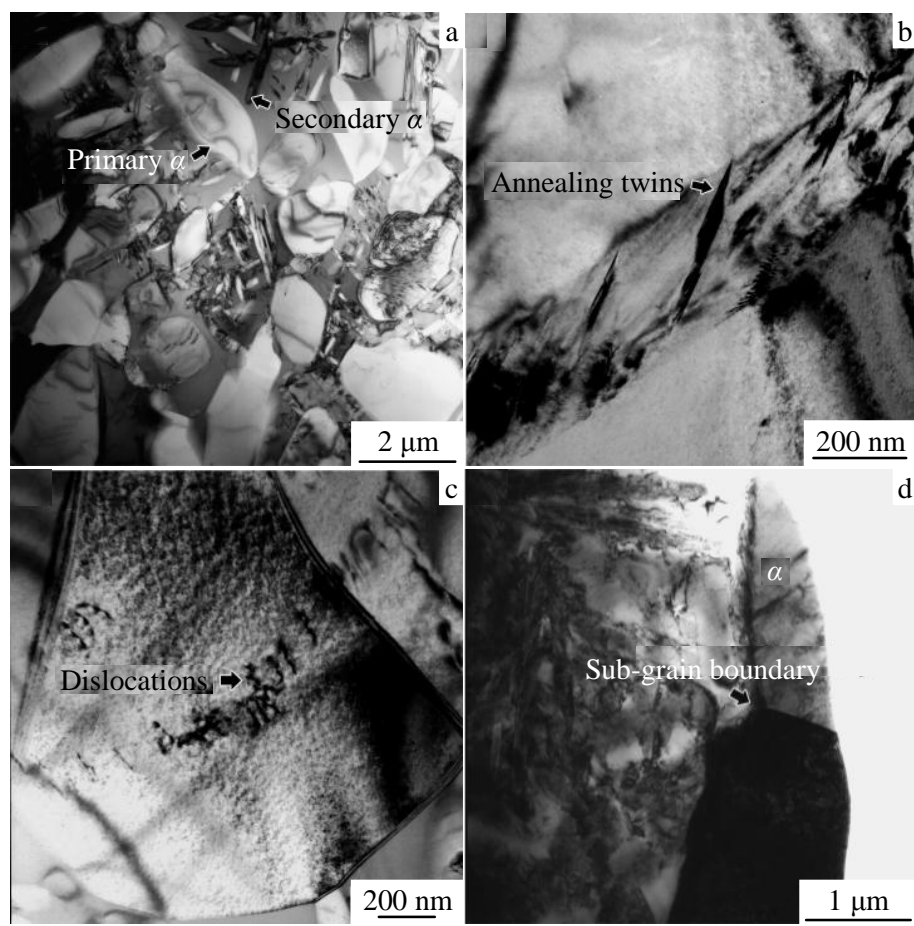

Fig.2 TEM images of TC18 alloy undergoing heat treatment: (a) the $\alpha$; (b) the annealing twins in secondary $\alpha$; (c) the dislocations in primary $\alpha$; (d) the sub-grain in primary $\alpha$

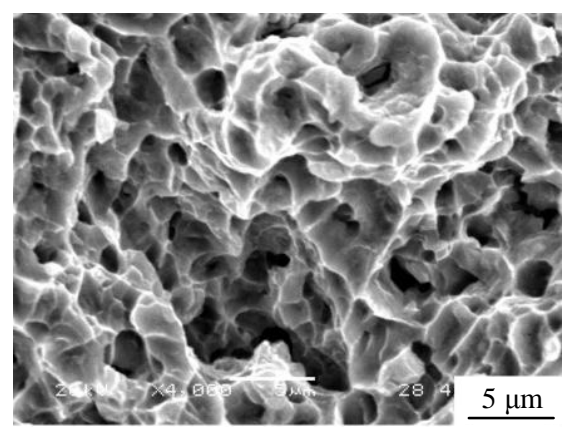

Fig.3 SEM fractograph of the tensile specimen

Moreover, the arc surface of primary $\alpha$ formed during the spheroidization process decreases the dislocation pilling-up during tensile test.

Fig.4 shows the microstructure of the longitudinal section of the specimen. Fig.4a presents the microstructural characteristics of the specimen during the process of the uniform deformation. Some $\beta$ grains are not obviously prolonged. The dislocations entering grain boundary is favorable for grain boundary migration. Furthermore, it will also make contribution to the restraint of $\alpha$ on the deformation of $\beta$. Fig. $4 \mathrm{~b}$ presents the microstructural characteristics of the specimen during the process of the concentrated deformation. Cavities can be observed. Lots of primary $\alpha$ grains are prolonged without breaking. This is also related to the dislocations absorbed by grain boundary.

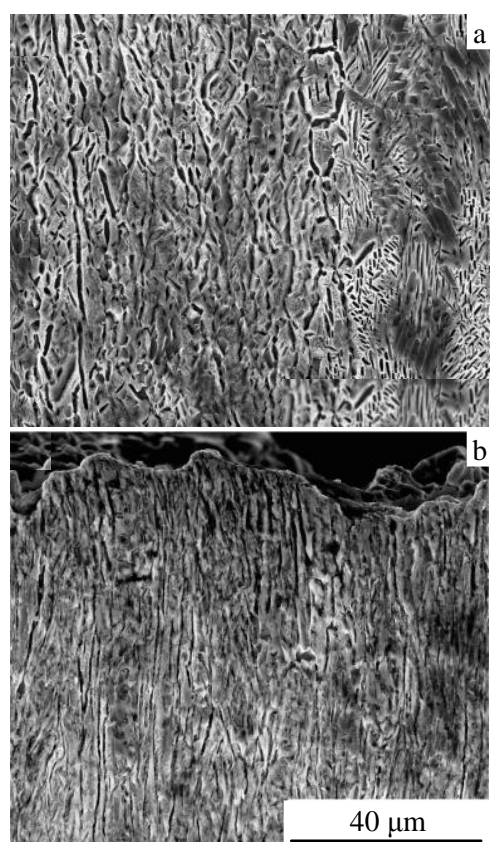

Fig.4 SEM images of the longitudinal section of the specimen: (a) the microstructure characteristics of uniform deformation and (b) the microstructure characteristics of concentrated defor- mation

The hardness of $\alpha$ with hcp structure is higher than that of $\beta$ with bcc structure. The secondary $\alpha$ tends to parallel to the external force during tensile test. When the aspect ratio (the 
ratio of length to diameter) of the secondary $\alpha$ is higher than the critical aspect ratio, the load can be transferred to $\alpha$ through $\alpha / \beta$ interface according to shear lag theory. The prolonged primary $\alpha$ grain also has load-bearing effect. The load bearing of $\alpha$ can promote the strength and the plasticity of the material. Moreover, the obstacle of secondary $\alpha$ to dislocation slip is favorable for promoting the strength. The refinement of $\beta$ also plays an important role in promoting the strength of the alloy according to Hall-Petch formula ${ }^{[14]}$.

The fracture mechanism of ductile material is micro-cavity inter-linage ${ }^{[15,16]}$. The primary $\alpha$ with arc surface decreases dislocation pilling-up, which can decrease the crack initiation. Moreover, the $\alpha$ phase can retard the crack propagation by increasing crack-tip blunting and crack deflection.

\section{Conclusions}

1) The dislocations enter the grain boundary during tensile test. The dislocation strengthening increases slowly. Therefore, the value of $\sigma_{\mathrm{y}} / \sigma_{\mathrm{b}}$ of tensile specimen is very high.

2) The load-bearing effect of $\alpha$ grain plays an important role in promoting the strength and the plasticity of the alloy during tensile test.

\section{References}

1 Ivasishin O M, Markovsky P E, Matviychuk Y V et al. Journal of Alloys and Compounds[J], 2008, 457: 296

2 Chang C T, Shiue R K, Chang C S. Scripta Materialia[J], 2006, 54: 853

3 Malinov S, Sha W, Markovsky P. Journal of Alloys and
Compounds[J], 2003, 348: 110

4 Neelakantan S, Martin D S, Rivera-Diaz-Del-Castillo P E J et al. Material Science and Technology[J], 2009, 25: 1351

5 Li C, Zhang X Y, Zhou K C et al. Material Science and Engineering $A[\mathrm{~J}], 2012$, 558: 668

6 Jia B H, Song W D, Tang H P et al. Rare Metals[J], 2014, 33(4): 383 (in Chinese)

7 Liu S F, Li M Q, Luo J et al. Material Science and Engineering $A[\mathrm{~J}], 2014,589: 15$

8 Zherebtsov S V, Murzinova M A, Klimova M V et al. Material Science and Engineering A[J], 2013, 563: 168

9 Liu C M, Tian X J, Tang H B et al. Journal of Alloys and Compounds[J], 2012, 572: 17

10 Li C, Zhang X Y, Li Z Y et al. Material Science and Engineering $A[\mathrm{~J}], 2013,573: 75$

11 Eivani A R, Valipour S, Ahmed $\mathrm{H}$ et al. Metallurgical and Materials Transactions A[J], 2011, 42: 1109

12 Sun S Y, Wang L Q, Qin J N et al. Material Science and Engineering $A[\mathrm{~J}], 2011,530: 602$

13 Shu T D. The Dynamics of Non-Equilibrium Boundary Segregation and the Intergranular Brittle Fracture[M]. Beijing: Science Press, 2006: 116 (in Chinese)

14 Gao J H, Thompson R G, Patterson B R. Acta Materialia[J], 1997, 45: 3653

15 Boehlert C J, Tamirisakandala S, Curtin W A et al. Scripta Materialia[J], 2009, 61: 245

16 Dubey S, Li Y, Reece K et al. Material Science and Engineering $A[\mathrm{~J}], 1999,266: 303$

\title{
TC18 钛合金的微观组织和力学性能
}

\author{
孙曙宇 ${ }^{1}$, 吕维洁 ${ }^{2}$ \\ (1. 台州学院, 浙江 台州 318000) \\ （2. 上海交通大学 金属基复合材料国家重点实验室，上海 200240)
}

\begin{abstract}
摘 要：使用真空自耗电弧炉制备了 Ti-5Al-5Mo-5V-1Fe-1Cr（TC18）钛合金, 然后进行了热加工和热处理。对热处理后材料的微观组 织和力学性能进行了研究。结果表明, TC18 合金热处理后, 初生 $\alpha$ 相呈现出球形、近似等轴、盘状以及短棒状等多种形貌, 这和 $\alpha$ 的 晶界偏析有关。拉伸试验中合金表现出了良好的强度和塑性，而材料的屈/强比值却高达 0.95 。这说明拉伸过程中试样位错强化增长相 对缓慢。研究认为, 拉伸过程中晶界吸收了增殖的位错, 这是导致材料高屈/强比的首要原因。
\end{abstract}

关键词：TC18 钛合金; 组织特点; 力学性能; 屈强比值

作者简介: 孙曙宇, 男, 1971 年生, 博士, 讲师, 台州学院机械学院, 浙江 台州 318000, 电话: 0576-88661930, E-mail: sun_shuyu@126.com 